
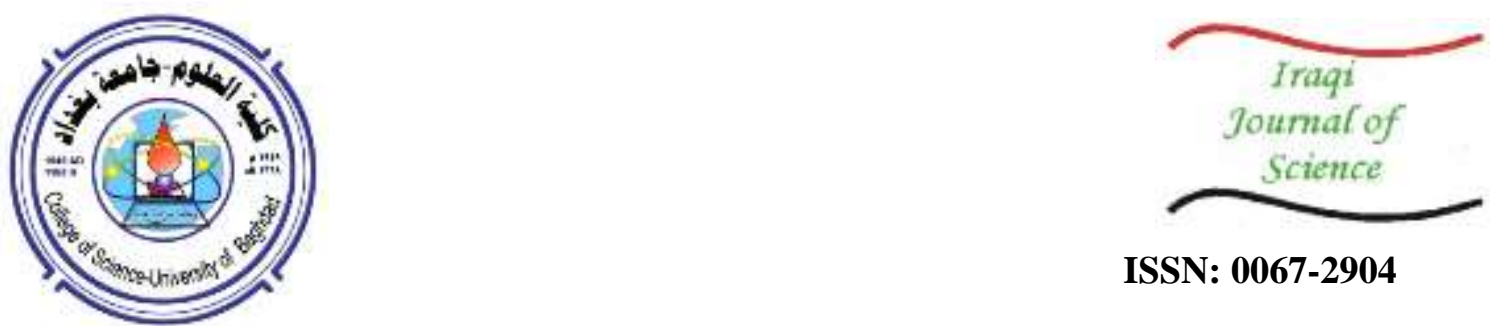

ISSN: 0067-2904

\title{
Effects of MWCNTs on the Tensile Properties and Thermal Conductivity of $\mathrm{BaTiO}_{3} /$ Epoxy Nanocomposites
}

\author{
Iman Ibrahem Nassif, Ban Mazin Al-Shabander* \\ Department of Physics, College of Science, University of Baghdad, Baghdad, Iraq
}

Received: 28/8/2019 Accepted: 17/12/2019

\begin{abstract}
This research studied the effects of modified $\mathrm{BaTiO}_{3}$ (BT) nanoparticles with coupling agent $\gamma$-APS $(0.5 \mathrm{wt}$. \%) on the tensile and thermal conductivity of epoxy nanocomposites with respect to content $(0.25,0.5,0.75,1,3$ and $5 \mathrm{wt} . \%)$. Multiwall carbon nanotubes (MWCNTs) at different concentration (0.2, 0.4, 0.8 and $1 \mathrm{wt} . \%)$ were added to the $\mathrm{BaTiO}_{3}$ /epoxy nanocomposites. The influence of MWCNTs on the tensile properties and thermal conductivity was investigated. The tensile strength and Young's modulus of $\mathrm{BaTiO}_{3} /$ epoxy nanocomposites film were increased at up to $3 \mathrm{wt}$. \% of added BT, but adding BT at more than $3 \mathrm{wt} . \%$ decreased the strength of epoxy. The tensile strength was increased with increasing MWCNTs content from $32 \mathrm{MPa}$ for pure epoxy to the value $56.8 \mathrm{MPa}$ for $1 \mathrm{wt}$. \% of MWCNTs content. The thermal conductivity of $\mathrm{BaTiO}_{3}$ /epoxy nanocomposites improved with increase of BT content. At 3 wt. $\%$ and 5 wt. $\%$ of $\mathrm{BaTiO}_{3}$ the thermal conductivity of nanocomposites decreased. The increase of MWCNTs concentration from 0.2 wt. \% to $1 \mathrm{wt}$. \% resulted in a thermal conductivity enhancement.
\end{abstract}

Keywords Barium titanate $\left(\mathrm{BaTiO}_{3}\right)$, silane $(\gamma$-APS) coupling agent, tensile strength, thermal conductivity

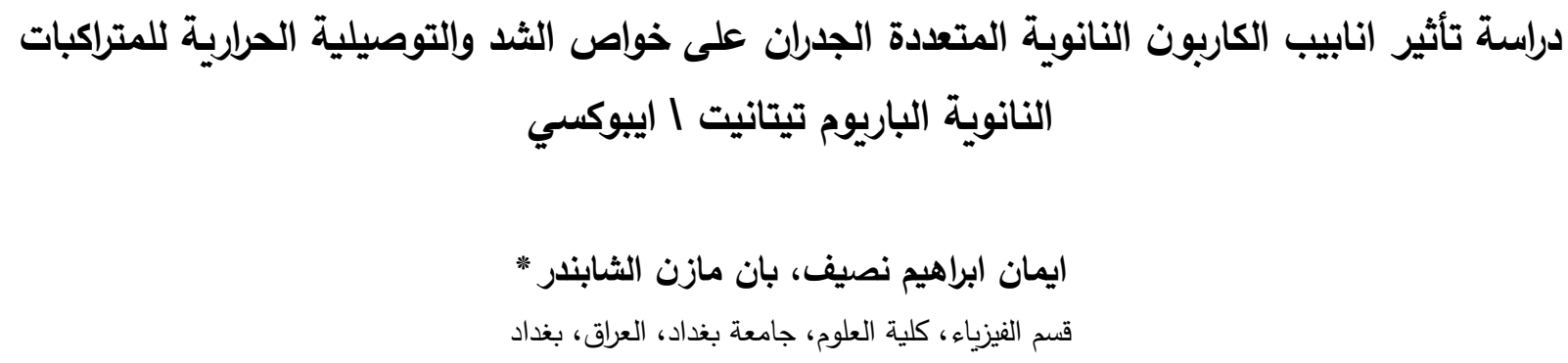

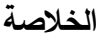

ها

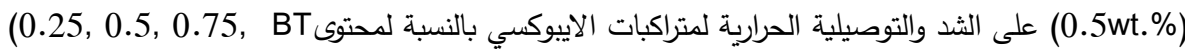
1, 3 and 5wt. \%)

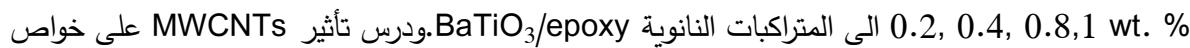
الثد والتوصيلية الحرارية. تزداد متانة الثد ومعامل يونك لفلم المتراكبات النانوية BaTiO 3wt. \% من BT من الإضافة اكثر من ذلك يودي الى تناقص قيمة المتانة. تزداد متانة الثد مع زيادة

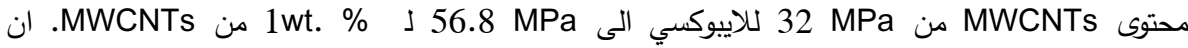
التوصيلية الحرارية تتحسن للمتراكبات BaTiO 3 /epoxy مع زيادة محتوى BT. متتناقص التوصيلية الحرارية

*Email:ban.m.alshabander@gmail.com 


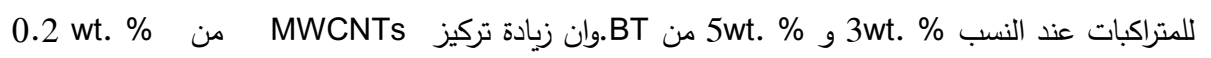

$$
\text { الى \%t. 1 } 1 \text { ينتج زيادة في التوصيلية الحرارية. }
$$

\section{INTRODUCTION}

Ceramic /Polymer composite materials type 0-3 (a 0-3 composite having 0-dimension particles embedded in 3-dimensions of a continuous phase (polymer matrix)) [1] have received much attention due to the combination of the dielectric properties of ceramics and the mechanical flexibility, chemical stability, low cost and easy processing of polymers [2]. Barium titanate $\left(\mathrm{BaTiO}_{3}\right)$ is a perovskite-type electro-ceramic material which shows ferroelectricity that provides high polarization and high dielectric constant. $\mathrm{BaTiO}_{3}$ is widely used in fabrications of multilayer ceramic capacitors (MLCC), infrared detectors, thermistors, transducers, electro-optic devices and sensors [3]. The incorporation of a ceramic filler phase into polymer matrix produced composites with better mechanical properties and piezoelectric characteristics.

Epoxy is one of the most important thermoset polymers, widely used as dielectric material in manufacturing electronic devices. This is because epoxy has peerless physical and chemical properties. However epoxy itself has low dielectric constant which is not suitable to be used in capacitor applications. As a result, high dielectric constant fillers (high $\mathrm{k}$ ) such as multi-walled carbon nanotube (MWCNT) were introduced to mix with epoxy matrix to produce high $\mathrm{k}$ dielectric materials [4].

Tensile testing is usually used to study the mechanical properties of nanocomposite materials (the tensile strength, percent elongation at break and Young's modulus) with certain geometry and stretching speed. The relationship between the stress and tensile strain are determined through what is called as Hooke law.

Modulus of elasticity (E) is a measure of the stiffness of an elastic isotropic material and is a quantity used to characterize materials. It is defined as the ratio of the stress along an axis over the strain along that axis in the range of stress in which Hooke's law holds.

$$
\begin{gathered}
\text { Young 's modulus }(E)=\frac{\text { stress }}{\text { strain }} \\
E=\frac{\sigma}{\varepsilon}=\frac{F / A}{\Delta l / l}
\end{gathered}
$$

where $F$ is the load at failure (force at which the films break), $A$ is the area of the film, $l_{f}$ is the final length of the film at failure and $l_{0}$ is the initial length of the film between grips [5].

The Lee's disc apparatus is working under the principle that when heat is transferred, by conduction through unit cross-sectional area of a material, then a temperature gradient is generated perpendicular to the area which, will results in a steady state after some time. Heat conducted through the sample at steady state is equal to the heat radiated from the Lee's disc.

The thermal conductivity (k) of the samples with thickness (d) and radius (r) were calculated using the following equations [6]:

$$
k=\frac{e d}{2 \pi r^{2}}\left[a_{s}\left(\frac{T_{A}+T_{B}}{2}\right)\right]+2 a_{A} T_{A}
$$

where $\mathrm{e}$ is given by

$$
e=\frac{I V}{\left[a_{A} T_{A}+a_{s} \frac{T_{A}+T_{B}}{2}+a_{B} T_{B}+a_{C} T_{C}\right]}
$$

where $\mathrm{a}_{\mathrm{A}}, \mathrm{a}_{\mathrm{B}} \mathrm{a}_{\mathrm{C}}$ and $\mathrm{a}_{\mathrm{S}}$ are the exposed surface areas of discs A, B, C and the sample, respectively. $T_{A}, T_{B}$ and $T_{C}$ are the temperatures of the discs $A, B$ and $C$, respectively, above ambient, $V$ is the potential deference across the heater and I is the current which flows through it. 
This study aims to investigate the tensile properties and thermal conductivity of $\mathrm{BaTiO}_{3} / \mathrm{epoxy}$ nanocomposites film. We also test the effects of different weight percentage ratios of MWCNTs on these properties for $\mathrm{BaTiO}_{3}$ /epoxy nanocomposites.

\section{EXPERMENTAL PART}

Materials The materials used in the preparation of $\mathrm{BaTiO}_{3} /$ epoxy nanocomposites and $\mathrm{BaTiO}_{3} / \mathrm{MWCNTs} /$ epoxy nanocomposites were

- Epoxy resin (Bisphenol A diglycidyl ether BADGE (EUXIT 50 K I)) manufactured by the Egyptian Swiss chemical industries company.

- Hardener( 4,4diamino diphenyl methane DDM) (EUXIT 50 K II, 7728) made by the Egyptian

Swiss chemical industries company.

- 3-aminopropyl trimethoxy silane ( $\gamma$-APS), Sigma Aldrich.

- $\mathrm{BaTiO}_{3}(<50 \mathrm{~nm})$ nanopowders, Guoteng Electronic Ceramic Company.

- MWCNTs (purity about $90 \%$ and particle size $<10 \mathrm{~nm}$ ), Cheap Tubes Inc.

Modified $\mathrm{BaTiO}_{3}$ nanoparticles with $\gamma$-APS

$\gamma$-aminopropyl trimethoxy silane ( $\gamma$-APS) coupling agent was used to modify the surface of $\mathrm{BaTiO}_{3}$ to obtain good dispersion of BT into the epoxy matrix. First, $\gamma$-APS at $0.5 \%$ wt. weight fraction was dissolved in a solution of water : ethanol) with a volume ratio of 90:10, then $1 \mathrm{~g}$ of BT nanoparticles was added to the mixture which was ultra-sonicated for $30 \mathrm{~min}$ at room temperature, then stirred for $1 \mathrm{~h}$ at $60^{\circ} \mathrm{C}$. The obtained BT suspension was centrifuged, washed by ethanol. and finally dried in an oven to remove the residual solvent [7].

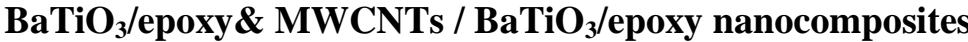

The modified BT particles with $\gamma$-APS coupling agent which were prepared from the prior step were added to ethanol and ultrasonic was applied for $1 \mathrm{~h}$ to obtain a stable suspension and prevent BT agglomeration. The epoxy resin was added to the suspension of BT in ethanol then stirred for $30 \mathrm{~min}$. After that it was subjected to ultrasonic treatment for $20 \mathrm{~min}$. The obtained solution was heated to $70^{\circ} \mathrm{C}$ for several hours to remove the residual solvent, and a specific amount of hardener was added to form a homogeneous mixture. This mixture was casted into a glass mold $(20 * 20 * 0.1 \mathrm{~cm})$. Finally, the curing process was carried out at a temperature of about $110^{\circ} \mathrm{C}$ for $30 \mathrm{~min}$. The ratios of BT nanoparticles to epoxy resin were $0.25,0.5,0.75,1$, 3and $5 \mathrm{wt}$. \%. The samples were cut according to ASTM D288 for tensile properties and Lee's Disc Method for thermal conductivity. The same above procedure was used to prepare MWCNTs / $\mathrm{BaTiO}_{3} /$ epoxy nanocomposites at $0.2,0.4,0.8$ and $1 \mathrm{wt}$. \% concentrations of MWCNTs.

\section{RESULTS and DISCUSSION}

Figure-1 (a) shows the strain-stress curve for the pure epoxy film. It is clear that the pure epoxy sample shows brittle behavior with tensile strength of $16 \mathrm{MPa}$. The addition of $\mathrm{BaTiO}_{3}$ nanoparticles to epoxy improved the properties of epoxy and its $n$ nanocomposites became more elastic, as shown in Figure- 1 (b). It can be seen that the tensile strength and Young's modulus of $\mathrm{BaTiO}_{3} /$ Epoxy nanocomposites film were increased at up to $3 \mathrm{wt}$. \% of the added BT. This may be attributed to the well dispersion of nanoparticles in epoxy. Consequently, the $\gamma$-APS coupling agent improved the compatibility between the $\mathrm{BaTiO}_{3}$ particles and the epoxy matrix. Also the increase in the tensile properties of the polymer were due to the small size of the particles which will participate in a very high-interfacial surface area and increase the mechanical properties [8]. As the nanoparticles content increases to more than $5 \mathrm{wt}$. \% of $\mathrm{BaTiO}_{3}$, the strength was degraded because of the formation of agglomeration and defects along with the presence of voids, etc. [9]. The tensile strength of epoxy with the ratio of $5 \mathrm{wt}$. \% of $\mathrm{BaTiO}_{3}$ was $32 \mathrm{MPa}$ and Young's modulus was $644 \mathrm{MPa}$. The tensile properties of $\mathrm{BaTiO}_{3} / \mathrm{Epoxy}$ nanocomposites such as tensile strength, elongation and Young's modulus (calculated by Eq.1) are illustrated in Table-1. All these properties were improved with the increasing the value of $\mathrm{BT}$ nanoparticles content, but adding $\mathrm{BaTiO}_{3}$ at more than $3 \mathrm{wt} . \%$ to the epoxy softened the matrix and reduced its tensile strength. Reductions in both stiffness and strength of the composite are attributed to the weak bonding between the BT particles and epoxy matrix [10]. 
(a)

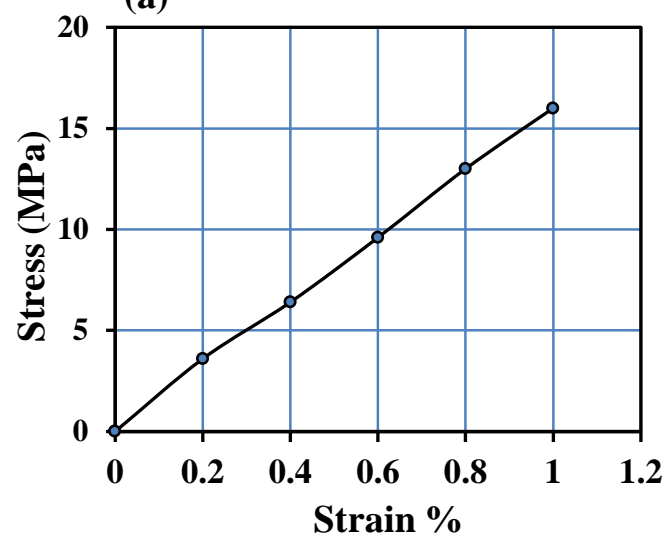

(b)

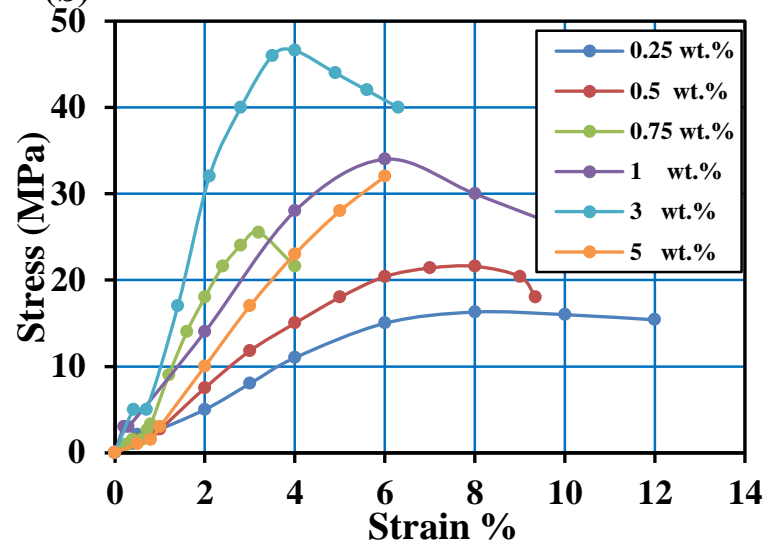

Figure 1-Strain - Stress Curves for (a) epoxy, and for (b) $\mathrm{BaTiO}_{3} /$ epoxy nanocomposites at deferent $\mathrm{BaTiO}_{3}$ content.

Table 1-Tensile properties for $\mathrm{BaTiO}_{3} /$ epoxy nanocomposites with different $\mathrm{BaTiO}_{3}$ content

\begin{tabular}{|c|c|c|c|}
\hline $\mathrm{BaTiO}_{3}$ wt. $\%$ & Tensile Strength(MPa) & Enlogation $(\mathrm{mm})$ & Young's Modulus(MPa) \\
\hline $\mathbf{0 . 2 5}$ & $\mathbf{1 6 . 3}$ & $\mathbf{1 2}$ & $\mathbf{3 1 2}$ \\
\hline $\mathbf{0 . 5}$ & $\mathbf{2 1 . 4}$ & $\mathbf{9 . 3 5}$ & $\mathbf{5 0 0}$ \\
\hline $\mathbf{0 . 7 5}$ & $\mathbf{2 5 . 5}$ & $\mathbf{4}$ & $\mathbf{8 7 4}$ \\
\hline $\mathbf{1}$ & $\mathbf{3 4}$ & $\mathbf{1 0}$ & $\mathbf{1 4 6 0}$ \\
\hline $\mathbf{3}$ & $\mathbf{4 6 . 1}$ & $\mathbf{6 . 3}$ & $\mathbf{1 7 1 0}$ \\
\hline $\mathbf{5}$ & $\mathbf{3 2}$ & $\mathbf{6}$ & $\mathbf{6 6 4}$ \\
\hline
\end{tabular}

Figure-2 shows the thermal conductivity of $\mathrm{BaTiO}_{3} /$ epoxy nanocomposite at room temperature as a function of $\mathrm{BaTiO}_{3}$ nanoparticles contents, which is calculated by Eqs.2 and 3. Thermal conductivity of the epoxy resin was found to be $0.2 \mathrm{~W} / \mathrm{m} . \mathrm{K}$ which is in a good agreement with the literatures [11]. It is clear that the thermal conductivity was slightly increased with the increase in BT content till $1 \mathrm{wt}$. $\%$. This is because the void formed during the preparation of the pure sample is greater than that for the other samples which are doped with $\mathrm{BaTiO}_{3}$. Another reason is that the thermal conductivity of $\mathrm{BaTiO}_{3}$ is 1.3 to $6 \mathrm{~W} /(\mathrm{m} \mathrm{K})$ [12], which is larger than that of epoxy resin [13]. At ratios of 3 and $5 \mathrm{wt}$. $\%$ of $\mathrm{BaTiO}_{3}$, the thermal conductivity of nanocomposites was decreased, which is attributed to air voids created during the preparation of composite sample and the agglomeration of BT nanoparticles, which was increased with high filler content. Although the distribution of BT in the matrix material is assumed to be in an arranged manner, it is actually dispersed in the resin almost randomly at the high contents of BT [14].

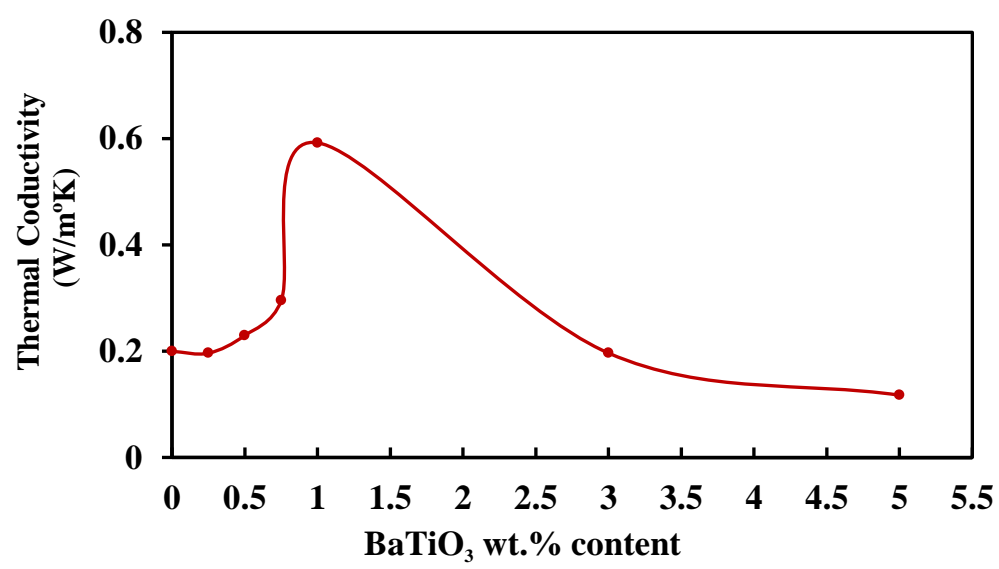

Figure 2-Thermal Conductivity of $\mathrm{BaTiO}_{3}$ /epoxy nanocomposites as a function of $\mathrm{BaTiO}_{3}$ content.

The Strain - Stress curves of $\mathrm{BaTiO}_{3} /$ epoxy nanocomposites as a function of MWCNTs content $\left(0.2,0.4,0.8\right.$ and 1 wt. \%) at a constant weight ratio of $\mathrm{BaTiO}_{3}(5$ wt. \%) are explained in Figure-3. The 
tensile strength was increased with increasing MWCNTs content from $32 \mathrm{MPa}$ for pure epoxy to the value 56.8 MPa for $1 \mathrm{wt}$. \% of MWCNTs content. This can be attributed to the substantial effects of MWCNTs surface groups on the interfacial bonding. Only if CNTs firmly adhere to the epoxy matrix, the load transfers from epoxy resin to the MWCNTs [15]. Table-2 explains the effects of MWCNTs at different concentrations on the tensile properties of $\mathrm{BaTiO}_{3} /$ epoxy nanocomposites. The tensile properties of the composites were improved significantly with the addition of MWCNTs, because the amorphous segment motions of the polymer chains are limited by the additives.

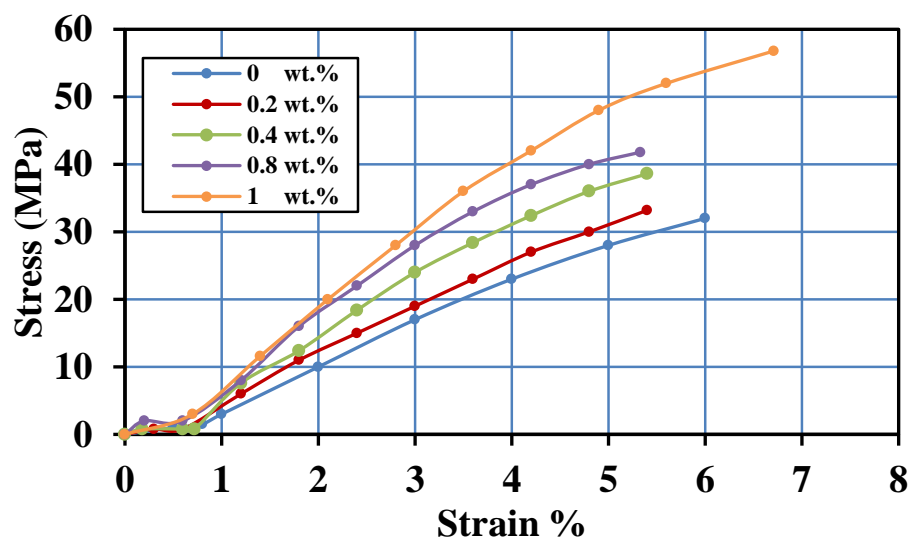

Figure 3-Strain - Stress Curves of $\mathrm{BaTiO}_{3} /$ epoxy nanocomposites as a function of MWCNTs content at 5 wt. $\% \mathrm{BaTiO}_{3}$.

Table 2- Tensile properties of $\mathrm{BaTiO}_{3} /$ epoxy nanocomposites as a function of MWCNTs content at 5 wt. \% $\mathrm{BaTiO}_{3}$

\begin{tabular}{|c|c|c|c|}
\hline MWCNTs wt. $\%$ & Tensile Strength(MPa) & Enlogation(mm) & $\begin{array}{c}\text { Young's } \\
\text { Modulus(MPa) }\end{array}$ \\
\hline $\mathbf{0}$ & $\mathbf{3 2}$ & $\mathbf{6}$ & $\mathbf{6 6 4}$ \\
\hline $\mathbf{0 . 2}$ & $\mathbf{3 3 . 2}$ & $\mathbf{5 . 5}$ & $\mathbf{7 9 9}$ \\
\hline $\mathbf{0 . 4}$ & $\mathbf{3 8 . 6}$ & $\mathbf{5 . 4}$ & $\mathbf{8 3 8}$ \\
\hline $\mathbf{0 . 8}$ & $\mathbf{4 1 . 8}$ & $\mathbf{5 . 3 3}$ & $\mathbf{1 1 4 8}$ \\
\hline $\mathbf{1}$ & $\mathbf{5 6 . 8}$ & $\mathbf{6 . 7 1}$ & $\mathbf{1 3 1 4}$ \\
\hline
\end{tabular}

Figure-4 shows the effects of the increase of concentration of MWCNTs on the thermal conductivity of $\mathrm{BaTiO}_{3} /$ Epoxy nanocomposites at a constant weight ratio of $\mathrm{BaTiO}_{3}(5$ wt. \%). The increase of MWCNTs concentration from $0.2 \mathrm{wt}$. \% to $1 \mathrm{wt}$. $\%$ resulted in a thermal conductivity enhancement. At room temperature, $1 \mathrm{wt}$ \% MWCNT/epoxy composite showed thermal conductivity of $0.2954 \mathrm{~W} / \mathrm{mK}$, which was higher than that of epoxy $(0.2 \mathrm{~W} / \mathrm{mK})$. For MWCNTS/epoxy/BaTiO nanocomposites, slightly increases were recorded in the thermal conductivity compared to pure polymers. Their thermal conductivity value is below its theoretical predictions based on the rule of mixture, due to their large interface scattering and contact resistance $[16,17]$.

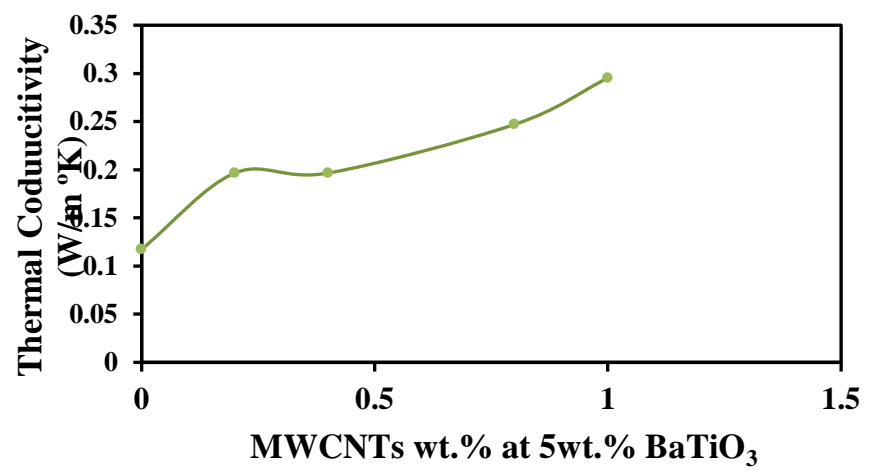

Figure 4-Thermal Conductivity of $\mathrm{BaTiO}_{3} /$ epoxy nanocomposite as a function of MWCNTs content for 5 wt. \% $\mathrm{BaTiO}_{3}$ 


\section{CONCLUSIONS}

In this study, $\mathrm{BaTiO}_{3} /$ Epoxy and $\mathrm{MWCNTs} / \mathrm{BaTiO}_{3} / \mathrm{Epoxy}$ nanocomposites were prepared and functionalized by a saline agent. It was observed that the tensile properties were improved with increasing BT content, but adding BT at more than $3 \mathrm{wt}$. \% to the epoxy softened the matrix and reduced its tensile strength. The tensile properties of the composites were improved significantly with the addition of MWCNTs. At ratios of $3 \mathrm{wt} . \%$ and $\% 5 \mathrm{wt} . \%$ of $\mathrm{BaTiO}_{3}$, the thermal conductivity of the nanocomposites was decreased.

\section{REFERENCE}

1. Zhang, L. and Cheng, Z.-Y. 2001. Development of polymer-based 0-3 composites with high dielectric constant, Journal of Advanced Dielectrics, 1: 389- 406

2. Upadhyay, R. H. and Deshmukh, R. R. 2013. A new low dielectric constant barium titanate - poly (methyl methacrylate) nanocomposite films, materials, 2: 99-109

3. Taylor, D.J. 2000. Handbook of Thin Film Devices: Ferroelectric Film Devices. San Diego. Academic Press.

4. Poh, C. L., Mustapha, M.J., Noor, A. F., Mohamed, A., Chuah ,T.P. and Cheen ,C. K. 2014. Dielectric properties of $\mathrm{BaTiO}_{3} /$ epoxy and MWCNT/epoxy composites, Advanced Materials Research, 1024: 393-396

5. Landel, R. F. and Nielsen,L. E.1994. Mechanical Properties of Polymers and Composites, $2^{\text {nd }}$. New York .Ed. Marcel Dakker, Inc.

6. Griffin, J. J. and George, J. 2002. Lee's Conductivity Apparatus (Electrical Method), LL44590I.S. 112217302, Griffin and George Ltd, Wembley Middlesex UK, 2-4.

7. Phan,T.T.M., Chu, N.C., Luu,V.B. ,Carriere P., and Nguyen,X.H. 2010. A study on the graftreaction of $\gamma$-aminopropyl-trimethylsilane onto $\mathrm{BaTiO}_{3}$ nanoparticles, Vietnam Journal. Chemistry, 48: 13-18

8. Mc Carrie, K.M.and winter, R. 2004. Properties of Epoxy-Clay Nanocomposite Adhesives for Bonded Strap Joints International Sampe Symposium and Exhibition -CD-ROM Edition, May: 1620

9. Chandradass, J. and Bae, D.S. 2008. Preparation and Properties of Barium Titanate Nanopowder/Epoxy Composites, Materials and Manufacturing Processes, 23: 116-122

10. Mohan, T.P. 2006. Synthesis and Characterization of Epoxy Clay Nanocomposites and Hybrids. Ph.D. thesis, IIT Madras, Chennai, India

11. Callister, W.D. 2003. Materials Science and Engineering. John Willy and sons, Inc., London

12. Y.S. Touloukian, R.W. Powell, C.Y. Ho, P.G. Klemens. 1970. Thermophysical Properties of Matter, vol. 2, Thermal Conductivity: Nonmetallic Solids, New York, IFI/Plenum Press

13. Sombatsompop, N. and Wood A. K. 1997.Measurement of thermal conductivity of polymers using an improved Lee's Disc apparatus, Polymer Testing ,16: 203-223

14. Al-Shabander, B.M. 2013.Investigation of Flexural Properties and Thermal Conductivity for Wood Dust Filled Epoxy, Journal of Al-Nahrain University, 16(3): 104-109

15. Kim, H., Wilburn, B.R., Castro, E., Garcia Rosales, C. A., Chavez, L.A., Bill Tseng, T. and Lin, Y. 2018. Multifunctional SENSING using 3D printed CNTs/BaTiO3/PVDF nanocomposites, Journal of Composite Materials , 0: 1-10

16. Caradonna, A., Badini, C., Padovano, E. and Pietroluongo, M. 2019. Electrical and Thermal Conductivity of Epoxy-Carbon Filler Composites Processed by Calendaring, Materials, 12: 15221539

17. Gyu Park, J. , Cheng, Q., Lu ,J., Bao, J. ,Li, S. , Tian ,Y. , Liang ,Z. , Zhang C. and Wang, B. 2012. Thermal conductivity of MWCNT/epoxy composites: The effects of length, alignment and functionalization" Carbon .50: 2083-2090 